\title{
Evaluating measures of exploratory behaviour in sows around farrowing and during lactation-A pilot study
}

\section{Valros, Anna}

2017-09

Valros , A , Pedersen , L J , Pöytäkangas , M \& Jensen , M B 2017 , ' Evaluating measures of exploratory behaviour in sows around farrowing and during lactation-A pilot study ' , Applied Animal Behaviour Science , vol. 194 , pp. 1-6 . https://doi.org/10.1016/j.applanim.2017.05.017

http://hdl.handle.net/10138/308000

https://doi.org/10.1016/j.applanim.2017.05.017

cc_by_nc_nd

acceptedVersion

Downloaded from Helda, University of Helsinki institutional repository.

This is an electronic reprint of the original article.

This reprint may differ from the original in pagination and typographic detail.

Please cite the original version. 
1 Evaluating measures of exploratory behaviour in sows around farrowing and during lactation 2 - A pilot study

3

4 Anna Valros ${ }^{\mathrm{a},{ }^{*}}$, Lene Juul Pedersen ${ }^{\mathrm{b}}$, Merja Pöytäkangas ${ }^{\mathrm{a}}$, Margit Bak Jensen $^{\mathrm{b}}$

5

6

${ }^{a}$ Department of Production Animal Medicine, Faculty of Veterinary Medicine, P.O. Box 57, 00014

University of Helsinki, Finland

${ }^{b}$ Department of Animal Science, Aarhus University, Blichers Alle 20, 8830 Tjele, Denmark

*Corresponding author: email: anna.valros@helsinki.fi, phone: +358-50-4151242

\section{Abstract}

There are very few studies on the need to perform exploratory behaviour of sows around farrowing and during lactation, except for during the nest-building period. Exploratory behaviour in pigs may reflect appetitive foraging motivated by hunger, or appetitive behaviour related to other motivations, such as nest building. However, exploration may also be motivated by curiosity, stimulated by novelty or search for novelty. The aim of this study was to test novel methods of evaluating exploratory motivation in sows around farrowing and during lactation. We used ten second or third parity sows, housed in conventional crates from day 8 before expected farrowing until weaning, on day 28 after farrowing. Motivation to perform exploratory behaviour was evaluated by measuring the use of a manipulable and chewable object (a wooden device, MCO) and responses during a novel object test (NO). In addition, we studied if exploratory motivation is related to the energy status of the sow, measured as sow weight change during lactation, piglet weight gain, and leptin level in saliva. The exploratory motivation of sows appeared to change 
during the period of study. Although all sows used the MCO, the use was very low throughout the study (below $3 \mathrm{~g}$ per day on average), and almost non-existent during the first weeks after farrowing. The latency to touch the object in the NO test was correlated between test days before and after farrowing, while the sow showed more interest in the object before than after farrowing. MCO use during the last week of lactation was higher in sows with a lower weight after weaning, suggesting a link between explorative motivation and energy status in the sow. These results indicate a need for further studies on how to best meet the possible exploratory need of sows during their time in the farrowing room.

\section{Keywords}

Exploration, sow, lactation, energy status, manipulable object, novel object

\section{Introduction}

In intensive pig production slatted floors and liquid manure management makes it difficult to use straw, or similar manipulable and destructible material for pigs, which provides a suitable outlet for exploratory motivation (Bracke et al., 2006; Studnitz et al., 2007). Lack of manipulable material has been discussed mostly in relation to growing pigs (Vanheukelom et al., 2012), likely due to the fact that this is closely related to the problem of tail biting in this age group (EFSA, 2014; D'Eath et al., 2014). However, access to appropriate manipulative material might also be crucial for the welfare of gestating sows (Munsterhjelm et al, 2015), and is certainly important for pre-farrowing sows during the nest building phase (for a review, see Yun and Valros, 2015).

Very few studies have looked at behaviour directed towards manipulable materials in sows during

late gestation and lactation, except in relation to nest-building. Bulens et al. (2014) found that crated (1) sows used only a very small amount of straw from a straw dispenser, both before and after 
51 farrowing. These authors did, however, speculate that this might have been due to the sows having

52 little experience extracting straw from the dispenser. In a small pilot study we found that lactating

53 sows in crates manipulated a piece of fresh wood hanging above the feeding trough very little

54 (Telkänranta et al, unpublished). This was surprising, as similar wood pieces were manipulated

55 frequently by fattening pigs, and also reduced the level of tail biting in these pigs (Telkänranta et

56 al., 2014). However, the low use of the wood pieces in sows may have been due to suboptimal

57 location of the wood. Farrowing crates greatly limit sow movements, and thus also restrict the

58 possibilities of sows to fulfil several needs, such as for nest-building (as reviewed by Yun and

59 Valros, 2015). However, as crates are widely used, there is a need for further investigation of how

60 to provide materials for sows in farrowing crates and the explorative motivation in these sows in

61 general.

62

In pregnant sows it has been suggested that exploratory behaviour is mainly appetitive foraging, due

64

65

66

67

68

69

70

71

72

to restrictive feeding, resulting in sows experiencing high levels of hunger during this period (EFSA, 2014). During lactation sows are usually fed ad libitum, and should not experience hunger as such. However, due to milk production there are high metabolic demands on sows during this period (Valros et al., 2003a). Even ad libitum feeding may not be enough to meet the nutritional needs of sows during this period of high metabolic demand. In addition to hunger, exploration may also be motivated by curiosity, representing a search for or interest in novelty, but the distinction between appetitive foraging behaviour and curiosity-motivated exploratory behaviour may be difficult to make (Studnitz et al., 2007). Several experimental studies show that pigs tend to be more interested in investigating novel objects than familiar ones (Wood-Gush and Vestergaard, 1991; Moustgaard et al., 2002; Kornum et al., 2007). Further, just before farrowing, sows are highly motivated to nest build, which increases their use of manipulable materials, such as straw (Haskell 
and Hutson, 1996). The exploratory activity of sows, and the motivation behind it, can thus be expected to change during the physiologically diverse period the sows spend in the farrowing unit.

If exploratory motivation in sows is mainly related to feeding motivation (EFSA, 2014), it could be expected that exploratory behaviour is linked to measures related to the energy status of the sow. Sows generally lose weight during lactation due to the high demand for milk production (Valros et al., 2003a). The level of weight loss is individual, and associated to the energy status of the sow prefarrowing (Prunier et al., 2001). Weight loss during lactation, weight at weaning, and milk production, indirectly measured as piglet growth, thus give crude indications of the energy status of the lactating sows. The hormone leptin, which is mainly produced in the adipose tissue, is involved in regulating feeding motivation and is positively related to energy status of the individual (Gautron and Elmquist, 2011). In sows, leptin level has been shown to be related to level of backfat and to long-term feeding level (Prunier et al., 2001; Summer et al., 2009; Cools et al., 2013). Leptin level is thus a potential indicator of long-term energy status.

The aim of this study was to test novel methods of evaluating the exploratory motivation of sows during the period from late gestation to weaning. We evaluated the use of a wooden manipulable and chewable device and the interest in novel objects, focusing on changes throughout the study period. In addition, we studied measures related to the energy status of the sows: weight, weight loss, piglet growth and leptin level, to make preliminary observations on a possible positive association between exploratory motivation and low energy status of the sow.

\section{Material and methods}

The study complied with a protocol approved by the Danish Animal Experiments Inspectorate (2013-15-2934-00822). 
101

102

103

104

105

106

107

108

109

110

111

112

113

114

115

116

117

118

119

120

121

122

123

124

125

\subsection{Animals, housing and management}

The study was performed at Aarhus University, AU-Foulum, Denmark, in the period May to July 2015, and included 10 clinically healthy 2 or 3 parity (Danish crossbred Landrace x Yorkshire) sows. All sows originated from the same herd and had been crated during farrowing in earlier parities. Approximately 4 weeks before expected farrowing the sows were brought to the research centre and were group housed until approximately 2 weeks before expected farrowing. Here they were moved to individual farrowing pens, and further to farrowing crates on day 8 before expected farrowing. On day 23 after farrowing, five randomly selected sows were moved to farrowing pens, as part of another study. The piglets were weaned at 25-29 days (average 26.8) of age.

All the sows were housed in one climate-controlled farrowing room in identical farrowing crates of $4.8 \mathrm{~m}^{2}$ in size including $2.1 \mathrm{~m}^{2}$ of slatted floor and a $0.6 \mathrm{~m}^{2}$ creep area (Figure 1). The covered creep areas were placed either to the right or left in the front corner of the pen. The farrowing pens were $6.6 \mathrm{~m}^{2}$ including a $2.7 \mathrm{~m}^{2}$ slatted floor area and a creep area of $0.87 \mathrm{~m}^{2}$. The creep areas in both crates and pens had a $2.5 \mathrm{~cm}$ thick rubber mat as surface and a heat source, which was turned off 10 days after farrowing.

Sows were fed three times a day at 0800 h, 1600 h, and 2100 h. During gestation the sows were fed 3.4 $\mathrm{kg} / \mathrm{day}$ with a standard diet for gestating sows of $(12 \% \mathrm{CP}, 102 \mathrm{FE} / \mathrm{kg}=7.9 \mathrm{MJ} \mathrm{PPE} / \mathrm{kg})$. During lactation the feed was a standard diet for lactating sows $(14.1 \% \mathrm{CP}, 8.2 \mathrm{MJ} \mathrm{PPE} / \mathrm{kg})$, and the sows received $2.5 \mathrm{~kg}$ at the day of expected farrowing. Every day after farrowing the ration was evaluated and was increased or decreased according to the requirements of the individual sow, which was assessed based on a visual assessment of left over feed. Individual feed intake was not measured. Furthermore, sows received $200 \mathrm{~g}$ of chopped wheat straw daily, placed on the floor near the head of the sow, but not in contact with the creep area. From day 10 after birth the piglets were provided with a solid feed ad 
libitum. From day 115 of gestation of the first expected farrowing until the last sow had farrowed in

127 the room, the light was turned on during 24 hours a day; this was necessary to record the farrowing

128 times on video for another study. After the last farrowing in a room, the light was on from 06001800h. A small window brought in natural daylight.

Eight sows gave birth to more than 14 piglets and the first morning after farrowing, the litter size of these was standardised to 14 piglets by taking randomly selected piglets from the litter to be fostered by non-experimental sows. Two sows gave birth to only 13 live-born piglets, and no piglets were added to these litters. The piglets were earmarked and within five days after farrowing, the males were castrated.

\subsection{Data collection and sampling procedures}

Piglet weights were recorded from the actual days after farrowing while all other measures are in relation to the expected farrowing date, giving a variation of -1 to +3 days in relation to actual farrowing date. The sampling and testing schedule is illustrated in Figure 2.

To evaluate the motivation to explore a manipulable and chewable object (MCO), a piece of fresh willow, approximately $30 \mathrm{~cm}$ long and $6 \mathrm{~cm}$ in diameter was attached to the front part of the crate structure before the sows were moved into the crates. The wood hung from a chain, about $2-3 \mathrm{~cm}$ above the floor, and was easily accessible by the sow (Figure 1). On day 23 the wood was moved with the sow to the pen for those sows being moved on that day. The wood was weighed before attaching it, on day 2 pre partum, and days 1, 23 and 27 postpartum. The average daily wood reduction was calculated (grams/day) as an estimate of MCO use for each sow and period, based on the exact amount of days for each sow: Period 1, P1 (days 8 to 2 prepartum), P2 (day 2 prepartum to day 1 postpartum), P3 (days 1 to 23 postpartum) and P4 (days 23 to 27 postpartum). 
152 To test for interest in novelty, sows were presented with novel objects (NO) in their farrowing crate.

153 Testing was performed twice during the experimental period: day 3 pre farrowing and day 19 post

154 farrowing. The test was performed between $1000 \mathrm{~h}$ and $1200 \mathrm{~h}$. The objects used included white 155 plastic flower pots, plastic cups of different colours and a plastic spaghetti spoon. The sows got a 156 different object on each test day, and the objects were given in random order. The sow was first 157 urged to stand up, and her attention towards the object direction was assured. The object, which was 158 hanging from a rope, about $40 \mathrm{~cm}$ above the floor, above the feed trough was then presented and 159 made available to the sow. During 10 min following presentation of NO the following variables 160 were recorded from video: latency to touch the object in seconds (NO latency); total duration of 161 interaction with the object (NO duration); and number of interaction bouts with the object (NO

162 frequency). NO interaction was defined as the sow touching the object with her snout, and the 163 object moving as a result of this. If the sow did not touch the object at all, the NO latency was recorded as $600 \mathrm{~s}$.

Piglets were weighed individually on days 1, 4, 7, 14 and 21 postpartum. Sows were weighed when moved to the farrowing unit (on day 8 before expected farrowing), and on the day of weaning.

Saliva samples for leptin analyses were obtained using Salivette ${ }^{\circledR}$ tubes by allowing the sow to chew on the swab for approximately 1 minute, or until the swab was clearly wet. The sows were used to the sampling procedure, as they had been trained and then sampled, as part of another study,

172 already during 3 previous days. Saliva samples were collected on day 3 before expected farrowing 173 and day 15 after farrowing, at $0530 \mathrm{~h}$ (before morning feeding) and at $1730 \mathrm{~h}$ (after afternoon 174 feeding). The samples were taken long enough after feeding to avoid feed residuals in the saliva.

175 Salivette tubes were centrifuged for $10 \mathrm{~min}$ at $1000 \mathrm{x}$ g and saliva samples were stored at $-80{ }^{\circ} \mathrm{C}$ 
until analysis. For statistical analyses morning and afternoon samples were pooled and average

177 daily leptin level is reported.

178

179

\subsection{Leptin analyses}

180 Before analysis, saliva samples were centrifuged for $5 \mathrm{~min}$ at $10000 \mathrm{x} \mathrm{g}$ to remove particulates and

181 the clear supernatant was diluted 3-fold with DPBS, pH 7.0-7.2 (Dulbecco's phosphate buffered

182 saline, Biochrom GmbH, Berlin, Germany). Leptin concentrations were measured as duplicates

183 using a commercial ELISA kit for porcine samples (Cloud-Clone Corp., Wuhan, China) according

184 to the manufacturers' instructions. The kit is a sandwich enzyme immunoassay for the quantitative

185 measurement of leptin in porcine serum, plasma, tissue homogenates and other biological fluids and

186 it has been used successfully to measure leptin concentrations in pig serum and plasma (Walsh et

187 al., 2013; Yang et al., 2013, Duan et al., 2014). The intra- and inter-assay coefficients of variations

188 were $9.2 \%$ and $11.8 \%$, respectively. Serial saliva dilutions were assayed by ELISA to assess

189 parallelism. Parallelism proved acceptable between samples diluted 3-fold to 10 -fold $\left(\mathrm{R}^{2}=0.9963\right)$.

190 The detection range for diluted samples was $0.06-4.00 \mathrm{ng} / \mathrm{ml}$. The detection limit for the diluted

191 samples was $0.03 \mathrm{ng} / \mathrm{ml}$, determined as the concentration of the leptin measured at two standard

192 deviations from the zero standard along the standard curve.

193

194

\subsection{Statistical methods}

All statistical analyses were performed with IBM SPSS 21.

196

197 Average daily MCO use, as well as NO latency, NO duration and NO frequency could not be assumed normally distributed, and the difference between periods for MCO use (P1, P2, P3, P4) and test days for the NO variables (day - 3 and day 19) was tested with Friedman's two-way 
analyses of variance by ranks, followed by Bonferroni-corrected pairwise comparisons when appropriate.

To test if the MCO and NO variables were consistent within sow over time, correlations between periods P1, P2 and P4 (9 of 10 sows did not used MCO in P3) for MCO use and test days for the NO variables were tested using Spearman rank correlations. A possible association between MCO use and NO was tested using Spearman rank correlations for MCO use P1 (P2 was excluded in all further correlations, as we were most interested in exploratory behaviour not directly related to nest building) against NO day -3, and MCO P4 use against NO day 19, respectively. Finally, measures of exploratory motivation ( $\mathrm{MCO}$ and $\mathrm{NO}$ ) were correlated to measures related to sow energy status using Spearman rank correlations for two time periods separately: MCO use in P1 as well as NO variables day -3 were correlated with leptin day -3 , and sow weight on day 8 before farrowing. Use of the MCO in P4 as well as NO variables day 19 were correlated with leptin day 15, sow weight at weaning, sow weight change, and piglet ADG during all periods. Only correlations which are significant $(\mathrm{p}<0.05)$ or tend to be significant $(\mathrm{p}<0.1)$ are reported in the text.

The effect of moving sows to pens at day 23 on MCO use was tested with Mann-Whitney U tests, but as no effect was found this is not reported.

\section{Results}

\subsection{Measures of exploratory motivation: Use of the manipulable and chewable object and}

\section{behaviour during the novel object test}

The use of the MCO differed between the different periods $\left(\mathrm{Chi}^{2}(3)=12.6, \mathrm{p}=0.006\right)$, with very little use of the MCO overall, especially during the first 3 weeks after farrowing (P3). Pairwise 
comparisons are reported in Table 1. The use of MCO did not correlate within sow between the different periods ( $\mathrm{p}>0.1$ for all).

227

228

The sows had a longer NO latency on day 19 postpartum than on day 3 prepartum $(Z=2.7, p=$ $0.008)$ and a shorter NO duration $(\mathrm{Z}=-2.4, \mathrm{p}=0.02)$ on day 19 postpartum than day 3 prepartum (Table 2). There was no difference in NO frequency between the two test days. The latency to touch the object showed consistency within sow as it was correlated between test days 3 prepartum and 19 postpartum $(\mathrm{r}=0.75, \mathrm{p}=0.02)$. No other inter-day correlations between the test parameters were found ( $\mathrm{p}>0.1$ for all). On day 3 prepartum all sows interacted with the NO at least once, while on day 19 postpartum one sow never touched the NO.

The use of the MCO did not correlate with any of the NO variables (latency duration, frequency) at either time point $(\mathrm{p}>0.05$ for all).

\subsection{Piglet performance and sow weight}

Descriptive data for piglet ADG, number of live and stillborn piglets, mortality of liveborn piglets until day 21, as well as sow weight and weight change, and leptin level are presented in Table 3. status.

244 Frequency of NO interactions on day 19 correlated negatively with leptin level on day $15(\mathrm{r}=-0.70$, 245 $\mathrm{p}=0.04)$

MCO use during P4 correlated negatively with sow body weight at weaning $(r=-0.80, p=0.005)$. 
All other correlations between the MCO and NO variables on one hand, and the measures of sow energy status on the other were non-significant ( $p>0.05$ for all).

251

\section{Discussion}

253

This pilot study supports previous observations of a minor motivation of sows in manipulating a piece of fresh wood during the period in the farrowing room. The novel object test indicated a higher interest in novelty before farrowing than during lactation. Further, we found some preliminary interactions between measures of exploratory motivation in sows and measures related to energy status of the sow, which warrant further research.

All sows used the manipulable and chewable object at some stage of the experimental period, but the use was minor. The use did, contrary to our expectations, not increase significantly before farrowing, i.e. during the nest building period. Even though a piece of wood does not provide a possibility to actually nest build, and increase in redirected nest-building type manipulation, such as bar biting, has been reported in pre-farrowing sows (Yun et al., 2015). During the first three weeks after farrowing use of the MCO was close to zero, only one sow used it at all. This might be due to a low feeding motivation and motivation for feeding-related exploratory behaviour (appetitive foraging) due to a change to ad libitum feeding at this point. During week 4 after farrowing the sows started using the MCO again, which may indicate an increased motivation to forage, due to an increasing metabolic load towards the end of lactation (Valros et al., 2003a), which cannot be fully compensated by feed intake. This theory is supported by the fact that MCO use during the last week before weaning correlated negatively with sow weight at weaning, with lighter sows using the MCO more. Weight change from before farrowing until weaning was not correlated to weaning weight and did not correlate with MCO use. However, weight loss was correlated with pre-farrow weight, 
273 indicating that weight loss mainly reflects the energy status of the sows at the beginning of

274 lactation, a correlation which has been reported previously (Prunier et al., 2001).

275

276

An alternative explanation for the low MCO use during the first weeks of lactation is that other

277 motivations are of higher priority at this stage, such as those related to piglet care and nursing. Also in rats, it has been shown that dams decrease their exploratory behaviour during the beginning of lactation, while returning to prepartum levels again when the pups are 20 days of age (Genaro \& Schmidek, 2002). Another motivation that might override the need for exploration in early lactation is resting motivation, causing a decreased general activity level. Sows spend most time lying laterally and show a low activity level during the beginning of lactation, with an increase after the second week post partum (Valros et al., 2003b, Lambertz et al., 2015). Regrettably, we cannot fully exclude that the piglets were using the MCO during the study period, as it was within their reach. However, it is very unlikely that piglets of this age would be able to chew pieces off a wood of this $\operatorname{size}(\varnothing 6 \mathrm{~cm})$.

The low usage level of MCO in crated lactating sows is in concordance with our previous experience (Telkänranta, unpublished) where we found sows not to use wood significantly during lactation. Also Bulens et al. (2014) found sows in farrowing crates to use only small amounts of straw when testing a straw dispenser ( $3.2 \mathrm{~g}$ per day), with no difference between the period before and after farrowing. A wooden piece and straw that is not easily distracted from a disperser may not represent available manipulative materials for sows. Thus, it is possible that alternative materials and alternative ways to provide materials may represent better out-lets for exploratory motivation in lactating sows. There is a need to investigate this topic further, by, for example, comparing motivation to access a wood piece and straw in a rack to straw provided on the floor. Furthermore, instead of merely comparing time spent and instead of simple preference tests, substitutability and 
quantitative preference may be established using double demand functions (Jensen and Pedersen,

299 2008). However, providing sows with appropriate manipulable material in crates is practically

300 challenging. The crate offers a very restricted space for providing material in a suitable location,

301 and any bedding-type material, such as straw, easily ends up out of reach of the sow. Bedding-type

302 material also easily falls through slatted flooring, commonly used in farrowing pens. The use of

303 straw and similar materials is further limited on-farm, as they may cause problems in slurry-based

304 manure handling systems.

305

306 The sows in this study were more interested in exploring a novel object before than after farrowing,

307 with all sows interacting with the object 3 days prior to farrowing. This supports the findings from

308 the use of the MCO, with sows being less interested in the wood during the three first weeks of

309 lactation than before farrowing. Also day 19 after farrowing, however, most sows interacted with

310 the object during the 10 minute test period. Latency to touch the object on day 3 before and day 19

311 after farrowing correlated positively, indicating that there is some individual stability in the

312 measure. However, the frequency of NO interaction did not differ between periods. Moveover,

$313 \mathrm{MCO}$ and NO variables did not correlate, which cautions interpretation of these two in relation to

314 exploratory motivation. Possibly, MCO primarily reflects appetitive foraging, while NO primarily

315 reflects exploratory response to novelty.

316

317 The fact that a higher frequency of NO interaction was associated to a lower level of leptin on day

31819 after farrowing could suggests a link between interest in novelty and the energy status of the

319 sow, i.e. that sows with a high energy status have a lower general curiosity. However, the results are

320 not highly convincing since leptin only correlated to NO frequency, not to NO latency and NO

321 duration. Leptin did not correlate to the MCO use either, thus we cannot conclude on a link between

322 leptin and exploratory motivation based on the present results. A high level of leptin signals satiety 


\section{3}

344

at high energy status (Berthoud, 2005) and has been shown to affect feed intake negatively also in pigs (Barb et al., 1998). Leptin has also been reported to be higher in sows with a higher backfat level during gestation (Cools et al., 2013) and lactation (De Rensis et al., 2005), which suggest further studies to clarify this link could be warranted.

As far as we know, there are no studies comparing levels of leptin in saliva and plasma in pigs, but in humans a good correlation has been reported (Gröschl et al., 2001, Randeva et al., 2003), showing a higher level of leptin in plasma than in saliva samples. Level of leptin in the saliva samples of the current study was also lower (overall average $1.7 \mathrm{ng} / \mathrm{ml}$ ) than has been reported for plasma samples: between 2.2 and $5.9 \mathrm{ng} / \mathrm{ml}$ in a corresponding period around farrowing (Govoni et al., 2007; Cools et al., 2013; Saleri et al., 2015).

\section{Conclusions}

The exploratory motivation of sows appears to change during the period of study, being higher before than after farrowing, and especially low during the first weeks after lactation. There is a need for further studies on how to best provide an outlet for exploratory motivation of sows during their time in the farrowing room, and to better understand the reason for the apparently low exploratory motivation after farrowing. These preliminary results suggest that explorative motivation in sows might be linked to the energy status of the sow, but this still needs to be confirmed.

\section{Acknowledgements}

The research visit to Denmark by Anna Valros was funded by the Foundations' Professor Pool in Finland, and by the Aarhus University Research Foundation. The authors wish to thank Carsten K. Christensen (Aarhus University) for valuable technical assistance, veterinary students Fanny Bäck and Emma Vikström (Helsinki University) for their valuable help with the practical work, as well as 
348 Mona Lilian Vestbjerg Larsen (Aarhus University) for sharing the work with the sows. We also

349 thank the staff at the AU-Foulum research facility for taking good care of the animals.

350

351

\section{References}

352

Barb CR, Yan X, Azain MJ, Kraeling RR, Rampacek GB, Ramsay TG. Recombinant porcine leptin

353 reduces feed intake and stimulates growth hormone secretion in swine. Domest Anim Endocrinol

354 1998;15:77- 86.

355

356

Berthoud HR. A new role for leptin as a direct satiety signal from the stomach. Am J Physiol Regul Integr Comp Physiol 2005;288:796-7.

358

359

Bracke MBM, Zonderland JJ, Lensens P, Schouten WGP, Vermeer HM, Spoolder HAM et al. Formalised review on environmental enrichment for pigs in relation to political decision making. Appl Anim Behav Sci 2006;98:165-82.

362

Bulens A, Renders L, Beirendonck SV, Thielen JV, Driessen B. An exploratory study on the effects of a straw dispenser in farrowing crates. J Vet Behav 2014;9:83-9.

365

366

Cools A, Maes D, Decaluwé R, Buyse J, van Kempen TY, Janssens GP. Peripartum changes in 367 orexigenic and anorexigenic hormones in relation to back fat thickness and feeding strategy of sows Domest Anim Endocrinol 2013;45:22-7.

369

D’Eath RB, Arnott G, Turner SP, Jensen T, Lahrmann HP, Busch ME, Niemi JK, Lawrence AB,

371 Sandøe P. Injurious tail biting in pigs: how can it be controlled in existing systems without tail

372 docking? Anim 2014;8:1479-97. 
374 De Rensis F, Gherpelli M, Superchi P, Kirkwood RN. Relationships between backfat depth and 375 plasma leptin during lactation and sow reproductive performance after weaning. Anim Reprod Sci 2005;90:95-100.

377

378 Duan Y, Li1 F, Li L, Fan J, Sun X, Yin Y. n-6:n-3 PUFA ratio is involved in regulating lipid 379 metabolism and inflammation in pigs. Br J Nutr 2014;111:445-51.

380

381 European Food Safety Authority. Scientific opinion concerning a multifactorial approach on the use 382 of animal and non-animal-based measures to assess the welfare of pigs. EFS A J 2014;12:3702 [101

383 pp.].

384

385

Gautron L, Elmquist JK. Sixteen years and counting: an update on leptin in energy balance. J Clin 386 Invest 2011;121:2087-93.

387

Genaro G, Schmidek. The influence of handling and isolation postweaning on open field, exploratory and maternal behavior of female rats. Physiol \& Behav 2002;75:681-688. metabolic hormones in pregnant and lactating sows. Reprod Domest Anim 2007;42:39-43. 
397 Haskell MJ, Hutson GD. The pre-farrowing behaviour of sows with straw and space for

398 locomotion. Appl Anim Behav Sci 1996b;49:375-87.

399

400 Jensen MB, Pedersen LJ. Using motivation tests to assess ethological needs and preferences. Appl 401 Anim Behav Sci 2008;113:340-356.

402

403 Kornum BR, Thygesen KS, Nielsen TR, Knudsen GM, Lind NM. The effect of the inter-phase 404 delay interval in the spontaneous object recognition test for pigs. Behav Brain Res 2007;181:210 40517.

407 Lambertz C, Petig M, Elkmann A, Gauly M, Confinement of sows for different periods during 408 lactation: effects on behaviour and lesions of sows and performance of piglets. Anim 2015;9: 13734091378.

410

411 Moustgaard A, Lind NM, Hemmingsen R, Hansen AK. Spontaneous object recognition in the 412 Göttingen minipig. Neural Plasticity 2002;9:255-59.

413

414 Munsterhjelm C, Heinonen M, Valros A. Application of the Welfare Quality® animal welfare 415 assessment system in Finnish pig production, part II. Associations between animal-based and environmental measures of welfare. Anim Welf 2015;24:161-72.

417

418 Prunier A, Meija Guadarrama CA, Mourot J, Quesnel H. Influence of feed intake during pregnancy 419 and lactation on fat body reserve mobilisation, plasma leptin and reproductive function of 420 primiparous lactating sows. Reprod Nutr Dev 2001;41:333-47.

421 
Randeva HS, Karteris E, Lewandowski KC, Sailesh S, O’Hare P, Hillhouse EW. Circadian rhythmicity of salivary leptin in healthy subjects. Mol Genet and Metabolism 2003;78:229-35.

Saleri R, Sabbioni A, Cavalli V, Superchi P. Monitoring blood plasma leptin and lactogenic hormones in pregnant sows. Anim 2015;9:629-34.

Studnitz M, Jensen MB, Pedersen LJ. Why do pigs root and in what will they root? A review on the exploratory behaviour of pigs in relation to environmental enrichment. Appl Anim Behav Sci 2007;107:183-97.

Summer A, Saleri R, Malacarne M, Bussolati S, Beretti V, Sabbioni A et al. Leptin in sow: Influence on the resumption of cycle activity after weaning and on the piglet gain. Livest Sci 2009;124:107-11.

Telkänranta H, Bracke MBM, Valros A. Fresh wood reduces tail and ear biting and increases exploratory behaviour in finishing pigs. Appl Anim Behav Sci 2014;161:50-9.

Valros A, Rundgren M, Špinka M, Saloniemi H, Rydhmer L, Hultén F et al. Metabolic state of the sow, nursing behaviour and milk production. Livest Prod Sci 2003a;79:155-67.

Valros A, Rundgren M, Špinka M, Saloniemi H, Algers B Sow activity level, frequency of lying down and anti-crushing behaviour - within sow-repeatability and interactions with nursing behaviour and piglet performance. Appl Anim Behav Sci 2003b;83:29-40. 
Vanheukelom V, Driessen B, Geers R. The effects of environmental enrichment on the behaviour of

447 suckling piglets and lactating sows: A review. Livest Sci 2012;143:116-31.

448

449 Walsh AM, Sweeney T, Bahar B, O’Doherty JV. Multi-functional roles of chitosan as a potential 450 protective agent against obesity. PLOS ONE 2013;8:1.

451

452 Wood-Gush DGM, Vestergaard K. The seeking of novelty and its relation to play. Anim Behav 453 1991;42:599-606.

454

455 Yang H, Li F, Xiong X, Kong X, Zhang B, Yuan X et al. Soy isoflavones modulate adipokines and 456 myokines to regulate lipid metabolism in adipose tissue, skeletal muscle and liver of male

457 Huanjiang mini-pigs. Mol and Cell Endocrinol 365;2013:44-51.

458

459 Yun J, Valros A. Benefits of prepartum nest-building behaviour on parturition and lactation in sows 460 (review). Asian-Australasian J Anim Sci 2015;28:1519-24.

461

462 Yun J, Swan K, Oliviero C, Peltoniemi O, Valros A. Effects of prepartum housing environment on 463 abnormal behaviour, the farrowing process, and interactions with circulating oxytocin in sows. Appl 464 Anim Behav Sci 2015;162:20-25.

465

466

467

468

469

470 


\section{Tables}

478 Table 1. Average daily use of a manipulable and chewable wood object (MCO) by sows during four

479 different periods from the week before farrowing until weaning $(n=10)$.

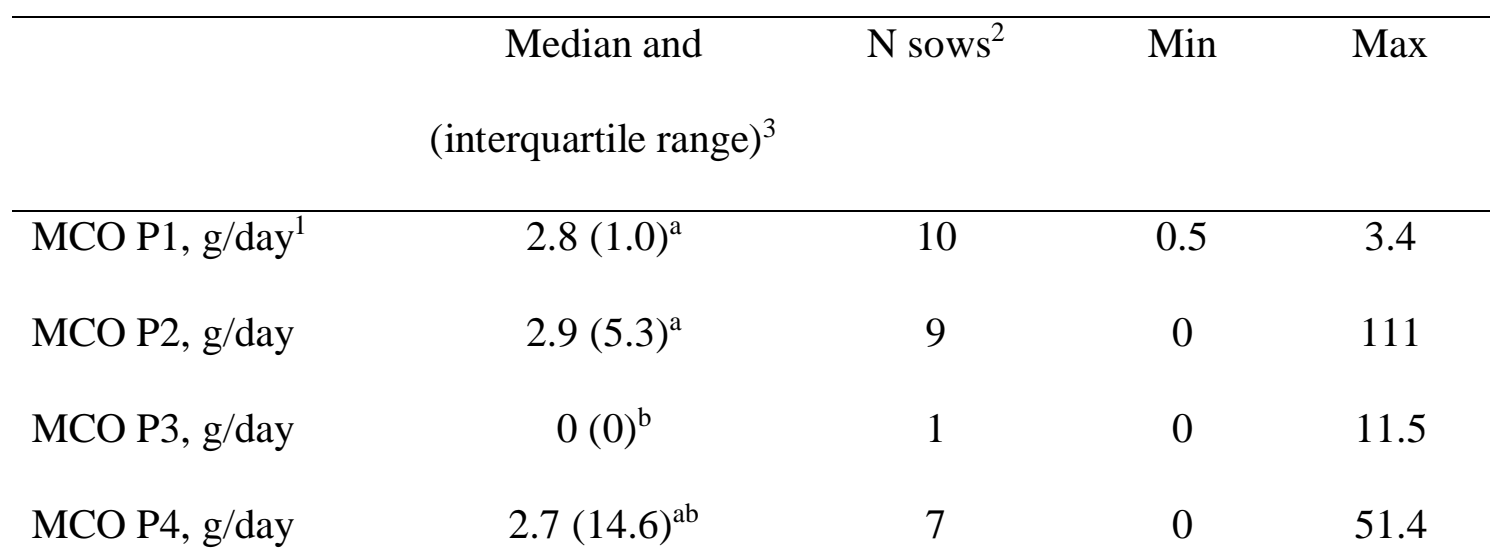

${ }^{1} \mathrm{P} 1$ : day 8 to day 2 prepartum; P2: day 2 prepartum to day 1 postpartum; P3: day 1 to day 23

481 postpartum; and P4: day 23 to 27 postpartum.

${ }^{2}$ Number of sows for which MCO was more than 0 during the different periods

${ }^{3}$ The lack of a common letter in the superscript indicates a difference between periods 
497 Table 2. Results from a novel object test (NO) performed with sows before and after farrowing $(\mathrm{n}=$ 498 10).

\begin{tabular}{lcccc}
\hline & \multicolumn{2}{c}{ Day 3 prepartum } & Day 19 postpartum \\
\cline { 2 - 5 } & Median and & Min-Max & Median and & Min-Max \\
& (interquartile & & (interquartil & \\
& range) & & e range) & \\
& $1(3)^{\mathrm{a}}$ & $0-23$ & $19(83)^{\mathrm{b}}$ & $3-600$ \\
NO latency, $\mathrm{s}^{1}$ & $44(124)^{\mathrm{a}}$ & $2-549$ & $8(41)^{\mathrm{b}}$ & $0-71$ \\
NO duration, $\mathrm{s}^{2}$ & $3(3)$ & $2-6$ & $3(3)$ & $0-5$ \\
NO frequency & & & &
\end{tabular}

${ }^{1}$ Latency to touch the object

${ }^{2}$ Total duration of interaction with the object

$501 \quad{ }^{3}$ Number of interaction bouts with the object

$502{ }^{4}$ The lack of a common letter in the superscript indicates a difference between days

503

504

505

506

507 
514 Table 3. Descriptive statistics for litter characteristics, piglet average daily weight gain (ADG), sow 515 weight and weight change and leptin level $(\mathrm{n}=10)$

\begin{tabular}{|c|c|c|c|}
\hline & $\begin{array}{c}\text { Median and } \\
\text { (interquartile range) }\end{array}$ & Min & Max \\
\hline Liveborn piglets & $17(9)$ & 13 & 22 \\
\hline Stillborn piglets & $2.5(2)$ & 0 & 6 \\
\hline \multirow[t]{2}{*}{ Mortality of liveborn until day 21} & $1.0(3)$ & 0 & 3 \\
\hline & $\begin{array}{c}\text { Mean and } \\
\text { (standard deviation) }\end{array}$ & & \\
\hline Piglet ADG day $1-4, \mathrm{~g}$ & $153(26)$ & 120 & 200 \\
\hline Piglet ADG day 4-7, g & $199(48)$ & 110 & 280 \\
\hline Piglet ADG day 7-14, g & $235(59)$ & 140 & 330 \\
\hline Piglet ADG day 14-21, g & $245(48)$ & 180 & 330 \\
\hline Piglet ADG day 1-21, g & $222(40)$ & 170 & 280 \\
\hline Sow weight day 8 prefarrowing, $\mathrm{kg}$ & $279(22)$ & 252 & 323 \\
\hline Sow weight at weaning (day 28$), \mathrm{kg}$ & $241(14)$ & 223 & 271 \\
\hline Sow weight change, $\mathrm{kg}$ & $-38(17)$ & -77 & -19 \\
\hline
\end{tabular}


Leptin day 3 prefarrowing, ng/mL

$1.46(0.70)$

0.27

2.21

Leptin day 15 postfarrowing, $\mathrm{ng} / \mathrm{mL}$

$2.04(1.14)$

0.49

3.81

516

517

518

519

$520 \quad$ Figures

521

Figure 1

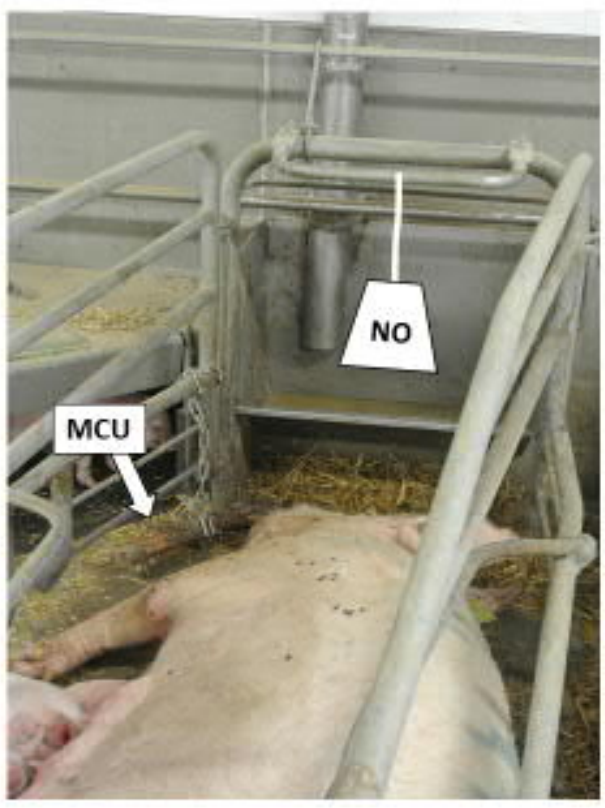

522

523 Figure 1. Illustration of the position of the manipulable and chewable object (MCO) and the novel

524 object (NO) during the novel object test. 
Figure 2

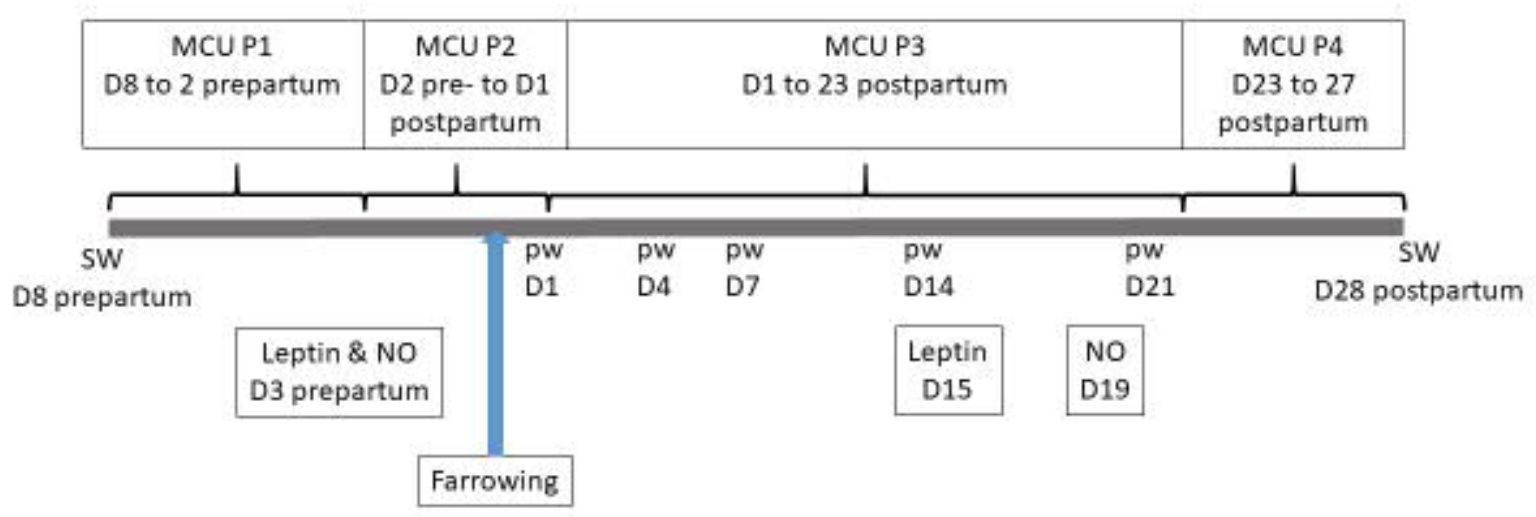

525

526 Figure 2. Diagrammatical presentation of the sampling schedule. The use of manipulable and

527 chewable object (MCO) was evaluated during 4 periods (P): P1 (days 8 to 2 prepartum), P2 (day 2

528 prepartum to day 1 postpartum), P3 (days 1 to 23 postpartum) and P4 (days 23 to 27 postpartum).

529 SW: sow weighing, pw: piglet weighing, NO: novel object test.

530

531

532 